\title{
GENERAL ELECTRIC RESEARCH LABORATORY, SCHENECTADY

\author{
NEW METALS AND CERAMICS BUILDING
}

\author{
By ROBERT L. FULLMAN \\ Materials and Processes Section, \\ AND \\ ROBERT M. PARKE \\ Materials Application and Evaluation Section, \\ Research Laboratory, General Electric Company, Schenectady, Naw York
}

A

NEW Metals and Ceramies Building was dedicated late last summer in Schenectady, N.Y., as the facilities of the General Electric Research Laboratory were enlarged. The new building reflects the current widespread interest in research into metals and ceramics, and is part of a 15 -million dollar expansion programme now being undertaken at the Laboratory.

The programme of work to be undertaken in the new building includes the following: (1) to ascertain and analyse the areas of most critical need for materials and processes; (2) to develop new processes for new businesses; (3) to develop new materials to improve products ; (4) to study existing materials and obtain a better understanding of their properties and processing ; (5) to operate pilot plants and obtain economic data.

Dr. J. Herbert Hollomon, manager of the Metallurgy and Ceramics Research Department, has stated that the constant growth of the General Electric Co.--and the ever-inereasing diversity of the Company's needs-have necessitated the expansion of the facilities available for such work. "In addition," he says, "it is now more important than ever that the Research Laboratory's scientific understanding should be used for helping to solve any critical problems relating to materials and processes that may stand in the way of Company progress. The organization of the new Metals and Ceramics Building includes the establishment of a group of scientists to seek out and solve problems pertaining to materials and processes wherever they may appear in the Company. Thus, in the new building, amid facilities of both laboratory and industry size, the promising findings of our outstanding group of metallurgists, ceramists, physicists and chemists can be applied to the kind of problems now creating a bottleneck at the designer's level."

One field in which the Metals and Ceramics Building is expected to make significant contributions is in studies of the effect of the 'scale factor' on the properties and processing of materials. Investigation of the effect of large increases in the scale of operations during the transition from laboratory work to production previously has been among the least explored fields of metals and ceramics research. Studies in this field will include the feasibility and the probable cost of factory-size operations.

The General Electric Metals and Ceramics Building is for this reason one of the few facilities in existence which makes available to the research worker production-size equipment unrestricted by the scheduling demands of actual production. When the building was being planned, the size of the machines was to a large extent determined by the quantities of material that would have to be produced in order to make possible a realistic evaluation from the point of view of production. The size of some furnaces, for example, was determined by the smallest quantity of metal that would permit the manufacture of at least one complete product, such as a transformer, for evalua. tion purposes. The advice of manufacturing components of the Company was, therefore, sought in ascertaining practical limits of equipment capacity for pilot-plant production.

In order to allow the most efficient use of the variety of equipment, the building has been constructed for maximum flexibility, using what has been referred to as the 'erector set' principle. In this method of construction thousands of bolt holes are aligned throughout the structure of the building, permitting easy re-location of equipment. Consequently, as one research project is completed, another may be set up with a minimum of time and effort.

The available processing equipment includes arcmelting furnaces capable of melting highly refractory metals under vacuum and in inert atmospheres. Furnaces of this type are needed because many alloys now under investigation cannot be melted by normal commercial techniques. Vacuum arc-melted ingots of $300 \mathrm{lb}$. can be produced at the rate of three a day, while it is expected that in the future, by a continuous process, it will be possible to produce ingots weighing four thousand pounds or more. An industrial-type three-phase arc furnace for the preparation of one-ton heats of steel, and induction furnaces for melting metals and alloys in vacuum, controlled atmospheres or in air are also available.

Forming equipment includes a hydraulic extrusion press of 1,250-ton capacity, specially designed for rapid extrusion of super-alloys; a 2,500-lb. drophammer; 250-1b. and 2,500-1b. forging hammers; swaging equipment; and a new reversing, two-stand, rod-rolling mill. The rod mill has been designed for high-speed operation, permitting super-alloys to be formed to final size before they cool significantly from the annealing temperature.

A Sendzimir cold mill for rolling metal foils to thicknesses less than a thousandth of an inch, and a Sendzimir planetary hot mill, one of the first, have also been installed in the new building.

Much of the equipment for metal processing will also be used for the melting, heating and shaping of ceramic materials; but certain ceramic presses, furnaces and other equipment have been installed in separate areas to avoid contamination of the material.

The research staff have available throughout the building compressed air, high- and low-pressure steam, city gas, nitrogen, oxygen, standard hydrogen, dried hydrogen $\left(-90^{\circ} \mathrm{C}\right.$. dew point), rough vacuum, distilled water, cooling water, and hot and cold tap water. 